\title{
26. MEASUREMENTS OF POROSITY IN SEDIMENTS OF THE LOWER CONTINENTAL MARGIN, DEEP-SEA FANS, THE ALEUTIAN TRENCH, AND ALASKAN ABYSSAL PLAIN
}

\author{
Roland von Huene, U. S. Geological Survey, Menlo Park, California \\ David J. W. Piper, Dalhousie University, Halifax, Nova Scotia \\ and \\ John Duncan, ESSO Production and Research Company, Houston, Texas
}

\section{INTRODUCTION}

One objective of Leg 18 was to establish rates of sedimentation in the thick turbidite sequence along North Pacific continental margins. Rates of sedimentation based on the depth to time horizons may be significantly inaccurate if they are not corrected for compaction. Below about 400 meters, for example, compaction has commonly compressed sediment layers to as much as 60 percent of their original thickness. Since the amount of compaction is a function of porosity, the Leg 18 staff took special interest in the laboratory measurements of porosity. However, as the porosity data were analyzed during the cruise, it became apparent that the routine laboratory procedures gave poor precision. This was caused principally by the sample disturbance during coring, which is the reason most frequently given for questioning the usefulness of the Challenger porosity data.

During Leg 18, the scientific staff improved the precision of porosity measurements and by the last week at sea, the results of more careful procedures and selectivity increased the precision by almost an order of magnitude over the routine procedures. (Our procedures are described in the Appendix to this study). Since the end of Leg 18, we have reevaluated and selected the more precise values of porosity, and this paper presents these data and a generalized graph of porosity as a function of depth in North Pacific environments for use in compaction corrections.

\section{MEASUREMENTS OF POROSITY}

\section{Laboratory Procedures}

The principal procedure for measuring porosity aboard Challenger is to pass the core in its unsplit liner through a Gamma-Ray Attenuation Porosity Evaluator (GRAPE). The intensity of a 1 -mm-wide gamma ray passing through the core is measured with a detector and, after processing, is printed on an analog strip chart. This chart is digitized onshore at $1-\mathrm{cm}$ intervals. An estimate of saturated bulkdensity is obtained from a comparison of incident and attenuated gamma-ray intensities. Porosities are calculated from the GRAPE saturated bulk densities and grain densities that are estimated from core mineralogy. Comparative measurements using a different technique are made

\footnotetext{
${ }^{1}$ Publication authorized by the Director, U.S. Geological Survey.
}

by sampling the center of the core with a 1-cc syringe. A known volume of sample is removed with the syringe and the wet and dry sample weights are measured aboard the ship to provide porosity as well as bulk density. Unfortunately, weighing aboard ship, especially during rougher sea conditions, is not accurate enough to provide useful grain densities; therefore, these were estimated from the mineralogy of a core. Complete descriptions of routine shipboard procedures are given by Gealy (1971) and Pimm, Garrison, and Boyce (1971).

\section{Precision of Laboratory Measurements}

The GRAPE is capable of measuring porosity to \pm 1 percent (Evans, 1965) and this precision was probably repeated on Leg 18. However, the selected GRAPE measurements reported here probably have a precision of \pm 2 percent because of errors in digitizing records and changes in the position of the core within the liner during processing. Syringe measurements, on the other hand, may deviate 10 to 15 percent. $^{2}$ In the syringe procedure there must have been volume errors and disturbance of the sample during the extraction process. Also sample weight measurements aboard ship have limited accuracy, especially during rough sea conditions. Quantitative evaluation of these kinds of errors could not be accomplished aboard and it was only through an analysis of repeated samples that the imprecision of the syringe method was discovered. The analysis is reported in the Appendix.

\section{Laboratory to In Situ Corrections}

The usefulness of porosity measurement depends on how well in situ porosities can be determined from laboratory porosity measurements. Of two major sources of inaccuracy, the main one is disturbance of the sample during coring and the second is expansion of the sample caused by removal of overburden pressure. Both processes increase porosity so that laboratory measurements give erroneously high values.

Ample warnings have been voiced by shipboard investigators about disturbed core samples, an effect that was seen

\footnotetext{
${ }^{2}$ Differences of porosity reported in this paper refer to the difference of two porosity $\%$ value, not to the $\%$ that one value is greater than another. Thus, wherever $\%$ is written, porosity $\%$ can be read.
} 
to increase porosity by 20 percent in Leg 18 cores. $^{3}$ However, the close agreement ( $1 \%$ standard deviation) between syringe sample values from the middle of cores from Site 181 and GRAPE values, which include the outer and most frequently disturbed part, indicate that careful selection can nearly eliminate the disturbed core sections (see Appendix). The effect of removing overburden pressure was investigated by Hamilton $(1964,1965)$ using sediments from the experimental Mohole. He showed that in situ porosity could be reliably estimated from laboratory consolidation measurements. In the experimental Mohole study, the laboratory porosity and the calculated in situ porosity at 160 meters differed by 5 percent. Little additional work has been done since Hamilton's study because few consolidation measurements have been made on the material from DSDP cores. ${ }^{4}$

During the first six Challenger legs, a downhole logging system was aboard but many difficulties accompanied its operation and the measurements often appeared uninterpretable. On Leg 4, however, a comparison between downhole gamma ray-neutron and laboratory GRAPE measurements was made by Gealy and Gerard (1970). They report differences in the two types of porosity measurements as great as 21 percent (at $150 \mathrm{~m}$ depth). A review of the data tabulated by Gealy and Gerard shows that the laboratory measurements from the first two cores compared well with the downhole measurements. If averaged GRAPE values from the Leg 4 core summary (which differ from the values used by Gealy and Gerard) are used, averaged in situ-laboratory differences are 1.5 percent at 90 meters and 2 percent at 100 meters depth. These differences agree well with those of Hamilton. Although the first two cores appear somewhat disturbed, the five cores that follow appear severely disturbed in the core photographs and the lithologist has frequently noted them as being disturbed. The core porosities also suggest disturbed sediment because they suddenly jump by 15 to 20 percent at the point where laboratory-in situ differences become large, whereas the downhole $\log$ porosity remains fairly constant. Therefore only the porosities from the first two cores compared are considered undisturbed core values.

Qualitative indications that laboratory measurements aboard the Challenger are not greatly (5 to $10 \%$ ) different from in situ conditions were determined from physical property measurements and general observations. Laboratory measurements of sound velocities are commonly

\footnotetext{
${ }^{3}$ The following appears on DSDP computer printout of syringe porosity values: The GRAPE data should be viewed with caution as it is the result of continuous diameter-scanning along the entire length of an unopened core which includes undisturbed sediment, and drilling slurries. Because of the nature of the GRAPE sample only the maximum wet-bulk density values, and corresponding minimum porosity values to a lesser extent, are probably valid as minimum wet-bulk density values and maximum porosity values are always suspected of being disturbed sediment and drilling slurries.

${ }^{4}$ Consolidation measurements, unpublished at the time of writing, have been made by Bryant (Leg 10), Keller and Bennett (Leg 16) and Lee (Leg 19). None of the samples were taken from depths much greater than those of Hamilton and not all of the tests include rebound measurements.
}

within $100 \mathrm{~m} / \mathrm{sec}$ of the velocity determined by using the drilled depth to a seismic reflector and the time from a seismic record (cf. McManus, 1970). Temperature and pressure correction would reduce the differences to about $50 \mathrm{~m} / \mathrm{sec}$ (Hamilton, 1963). A difference of $50 \mathrm{~m} / \mathrm{sec}$ is equivalent to a porosity change of about 8 percent (Hamilton, 1970).

Another indication that the Challenger laboratory measurements are in reasonable agreement with in situ values is the consistency of our data with data from deep oil wells (McCulloh, 1967). The Leg 18 porosities fall within the probable range of porosities for most sedimentary rocks as given by McCulloh.

The expansion of some cores caused them to partly extrude from the liner when the core was initially brought aboard. This was particularly noticeable when they contained substantial amounts of gas. Only small amounts of expansion were noted in most other instances. In general, expansion extended the core not more than 1 or $2 \mathrm{~cm}$ beyond the core liner (less than $5 \%$ of the section). Expansion was imperceptible where the muds were firm or stiff as they generally were between 170 and 300 meters deep where the sediment became firm enough to break in a brittle manner. Most fissile muds retained their structure and, consistent with cores from drill holes on land, they generally retained their in situ porosity as well.

From these mostly qualitative indications, it seems that the difference between laboratory and in situ porosities are generally less than $10 \%$ (excluding significant disturbance of the core). The laboratory in situ difference probably increases with depth until the sediment becomes consolidated and then the difference gradually decreases to zero. Superimposed on this generalized curve are the effects of changing lithology and cementation.

Few data are available on which to base a laboratory in situ correction. Hamilton's (1964) measurements are strengthened by the acceptable data of Gealy and Gerard (1970) and by the consolidation graph of Site 181, Core 12, made by Lee and others (this volume). With these data, a generally valid correction factor for laboratory measurements is estimated. From zero at the surface, it is projected linearly to 5 percent at 160 meters. Beyond this depth the correction factor is conjectural because quantitative relaxation measurements are scant. However, since most of the sediments cored on Leg 18 had consolidated significantly between 180 meters and 300 meters it is assumed here that the correction factor reaches a maximum midway between these depths or at 240 meters. A linear projection of the correction factor from 160 meters gives an 8 percent maximum at 240 meters. Below this depth are the data from Site 181, Core 27, where the laboratory correction factor is 2 percent and the past overburden pressures are equivalent to a burial depth of at least 1500 meters (Lee and others, this volume). From 240 meters, the factor is projected linearly to 2 percent at 1500 meters.

This correction may be biased toward the maximum limit because of possible variance in moisture content between the consolidation test samples and the shipboard samples. This difference is due to excess water being available during the consolidation measurement whereas the core was confined to a plastic liner in a dry environment 
during relaxation of pressure and was given no opportunity to take on water prior to the GRAPE measurements. In addition, the consolidation test allows the sample to come to full equilibrium during relaxation which sometimes takes days whereas the core has a large surface in contact with the liner providing a frictional constraint and GRAPE porosities were usually measured from 1 to 4 hours after drilling.

Although there appears to be much uncertainty in the estimated correction factor, it probably does not diminish the usefulness of these porosity measurements for the purpose intended. Since the object of this study is to determine general values of porosity at various depths, a possible error of 4 percent is acceptable because the measured porosities commonly scatter about the averaged value by this amount. These data are not intended for problems where the precision must be held to less than 5 percent.

\section{GRAPHS OF LABORATORY POROSITY}

The data from Leg 18 are plotted for each site, and not with respect to sand, silt, or clay as is usually done, because the objective here is to obtain general porosity-depth relation in specific environments (Figures 1-5).

Since core disturbance and the presence of diatoms were not fully eliminated and both tend to increase porosity, some values are probably too large. An estimated core disturbance effect up to 3 percent and an estimated grain density error up to 3 percent, combined with a GRAPE precision of \pm 2 percent, give an estimated laboratory accuracy between -2 percent and +6 percent.

Generalized curves were fit to the data of all sites (Figures 1-5) and, with the exception of Site 173, the curves match within \pm 2 percent. The porosities of sediments from Site 173 (Figure 6) are about 10\% higher than those of the other sites. This is probably a function of the more pelagic environment in which they were deposited.

\section{SUMMARY}

A summary graph combining all but the Site 173 laboratory porosity measurements is shown in Figure 7. A generalized laboratory curve is fit through these data. Near the sea floor the plotted values range about \pm 15 percent from the curve whereas the few values around 600 meters indicate a range of about 8 percent. For comparison, porosity in turbidites at the base of the Sigsbee Escarpment that were calculated from the shore laboratory watercontent measurements on samples from Site 1 (Ewing et al., 1969) are also shown. All Site 1 values, except for the lowest core, are within 2 percent of the generalized Leg 18 laboratory curve.

An in situ porosity curve (dotted line) is constructed by adding the estimate for expansion from consolidated measurements (Figure 7). The unusual steepness of this curve below 240 meters strengthens the previous suspicion that the correction is too large. Another indication of over-correction is suggested by the comparison of the in situ curve with the summary graph of Richards and Hamilton (1967) (Figure 8). In our opinion the actual in situ curve probably falls between their in situ curve and our

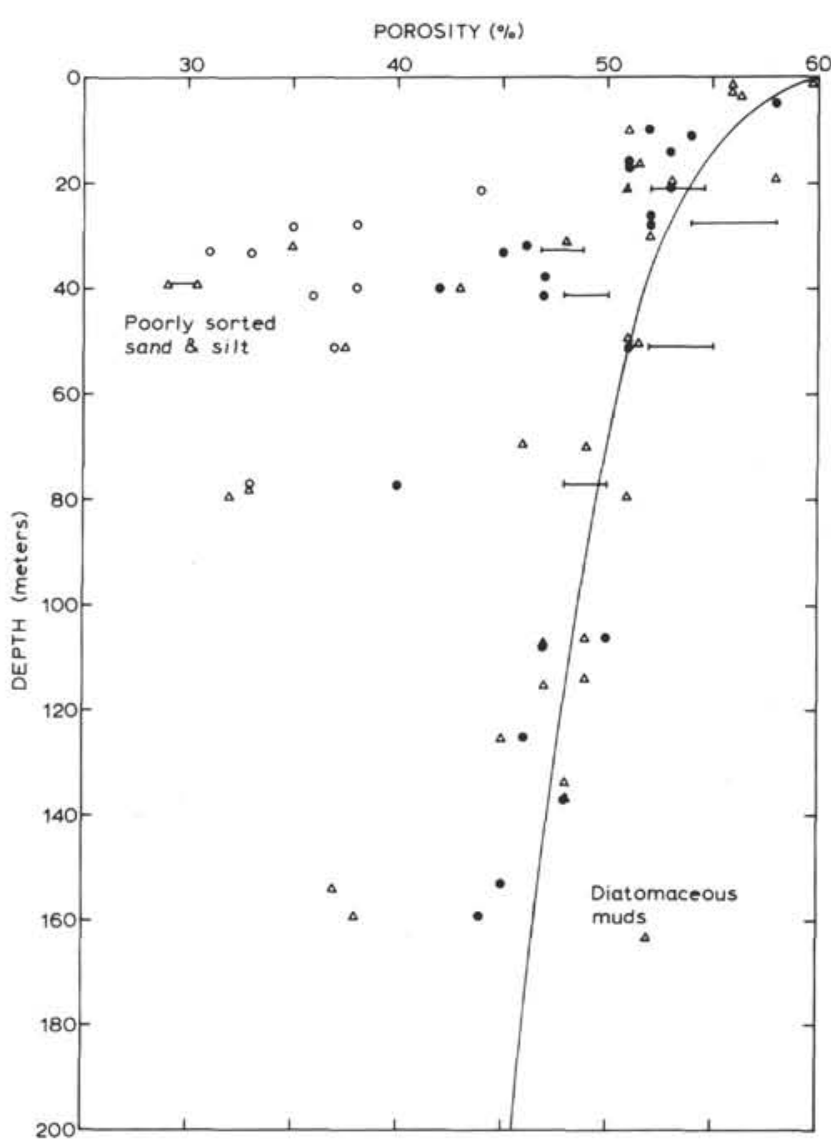

Figure 1. Porosity versus depth for Site 181. Open triangles $(\Delta)$ are syringe samples. Closed circles $(\bullet)$ are 1.5 meter section averages measured by GRAPE. Open circles (O) are GRAPE spot values for sand. Bars represent ranges of spot values for mud. The range of values between 20 and 60 meters is the maximum observed. The generalized curve is shown for comparison.

laboratory curve. Therefore, the Leg 18 data are corrected using an assumed curve, the dashed curve in Figures 7 and 8 . It is interesting to note that the assumed in situ curve is remarkably close to the curve published by Hamilton in 1959.

In using this generalized North Pacific deep-sea turbidite porosity curve to correct for compaction, it may be possible to modify certain variables for better application to specific problems. The largest variables are in original porosity, diatom content, and sand content. Original porosity, here assumed to be 60 percent, varies from 45 percent in muddy sands to approximately 75 percent in diatomaceous sediment. Diatomites retain relatively high porosities after burial; a diatom ooze adjacent to silt and mud commonly causes a sudden 20 percent porosity increase. In contrast, a sand adjacent to clay usually causes no more than a 10 percent decrease in porosity. Many of the Leg 18 sands are poorly sorted fine silty sands that sometimes have a porosity less than mud whereas the well-sorted sands have a greater porosity. 


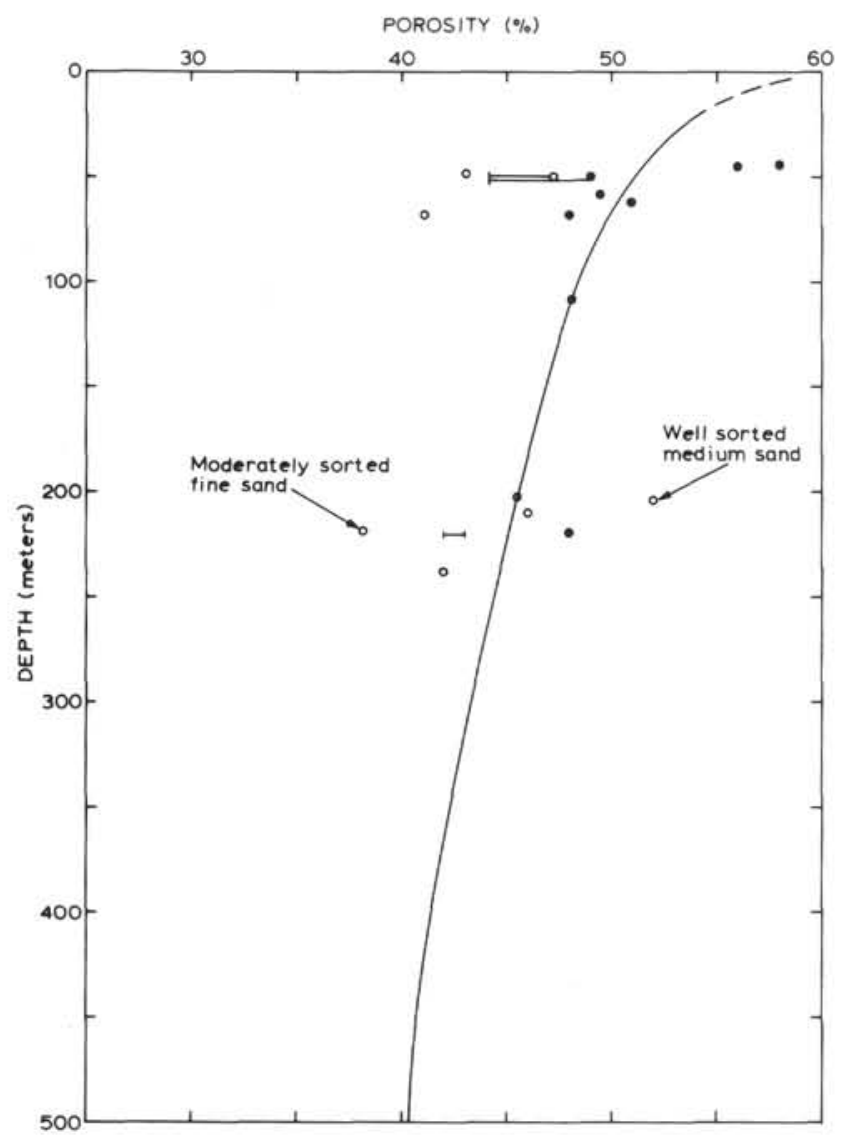

Figure 2. Porosity versus depth for Site 174, Astoria Fan. Closed circles ( ) are GRAPE section averages, open circles (O) and bars are GRAPE spot samples for sand and mud, respectively. The generalized curve is shown for comparison. The effect of sorting and grain size are shown near 210 meters. There are more porosity values for muds and poorly sorted silty sands than for clean sands because it is easily disturbed or lost in the coring process. Most well-sorted sands were disturbed to the extent that they were not acceptable for the porosity-depth graph. Sediments beneath Astoria Fan were not graphed.

\section{ACKNOWLEDGMENTS}

We are grateful to E.L. Hamilton and R.E. Boyce for his continual encouragement, advice, and review of this study. We also appreciate the thorough and critical reviews of L.T. Youd and L.H. Beyer that greatly improved the preciseness and readability of this paper.

\section{REFERENCES}

Evans, Hilton, B., 1965. GRAPE* - A device for continuous determinations of material density and porosity. Society of Professional Well Log Analysts: Sixth Annual Logging Symposium Transactions, May 4-7, 1965, Dallas, Texas, Vol. 2 of 2 volumes, p. 1B-25B.

Ewing, W. M., Worzel, J. L., et al., 1969. Initial Reports of the Deep Sea Drilling Project, Volume I. Washington (U.S. Government Printing Office).

Gealy, E. L., 1971. Saturated bulk density, grain density and porosity of sediment cores from the western

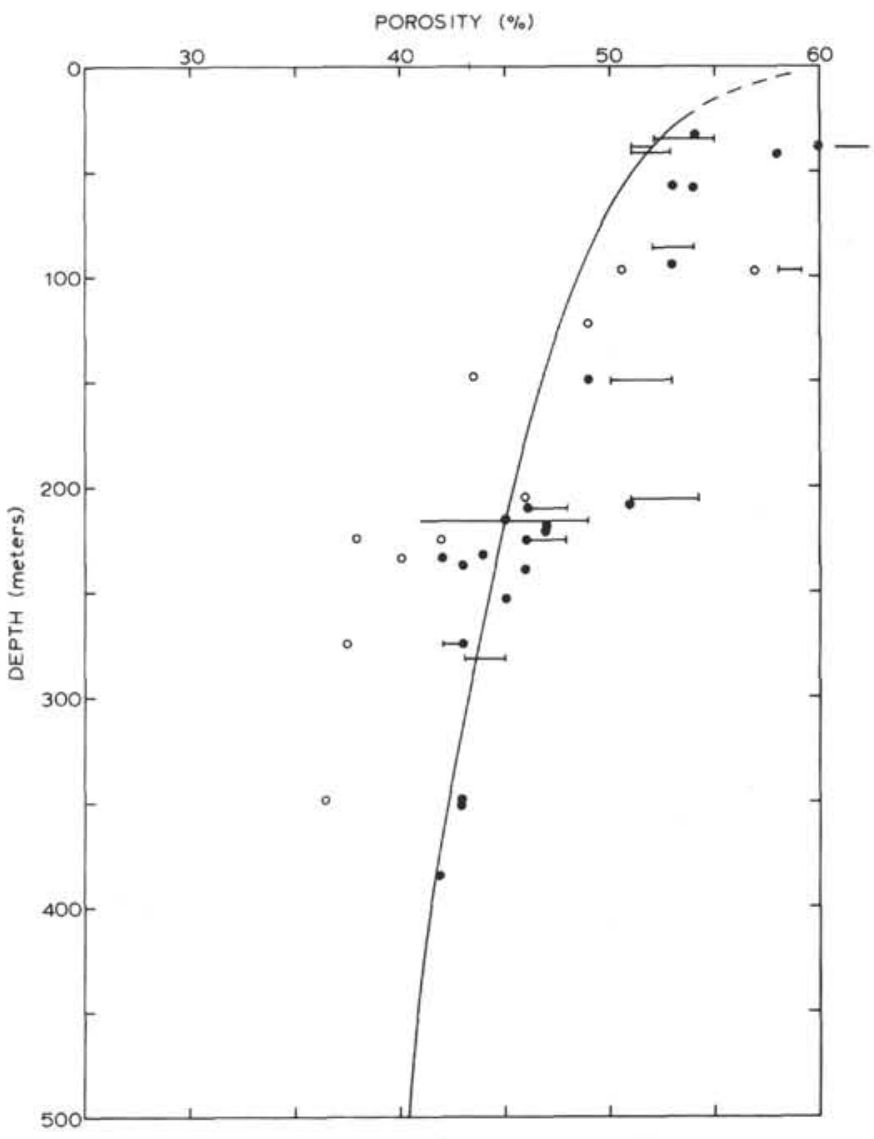

Figure 3. Porosity versus depth for Site 177, Paul Revere Ridge an uplifted deep sea fan. Symbols as in previous figure. There are again more porosities for muds and poorly sorted sand than for clean sands as at DSDP Site 174. Biogenic rich layers were not plotted to circumvent the grain density uncertainty.

equatorial Pacific. In Winterer, E. L., Riedel, W. R., et al., 1971. Initial Reports of the Deep Sea Drilling Project, Volume VII. Washington (U.S. Government Printing Office).

Gealy, E. L. and Gerard, R. D., 1970. In Situ petrophysical measurements in the Caribbean. In Bader, R. G., Gerard, R., D., et al., 1970. Initial Reports of the Deep Sea Drilling Project, Volume IV. Washington (U.S. Government Printing Office).

Hamilton, E. L., 1959. Thickness and consolidation of deep-sea sediments. Bull. Geol. Soc. Am. 70 (11), 1399.

Hamilton, E. L., 1963, Sediment velocity measurements made in situ from the bathyscaph TRIESTE. J. Geophys. Res. 68 (20) 5991.

Hamilton, E. L., 1964. Consolidation characteristics and related properties of sediments from experimental Mohole (Guadalupe Site). J. Geophys. Res. 69 (20), 4257.

Hamilton, E. L., 1965. Sound speed and related physical properties of sediments from experimental Mohole (Guadalupe Site). Geophysics. 30 (2), 257.

Hamilton, E. L., 1970. Sound velocity and related properties of marine sediments, North Pacific. J. Geophys. Res. 75 (23), 4423. 


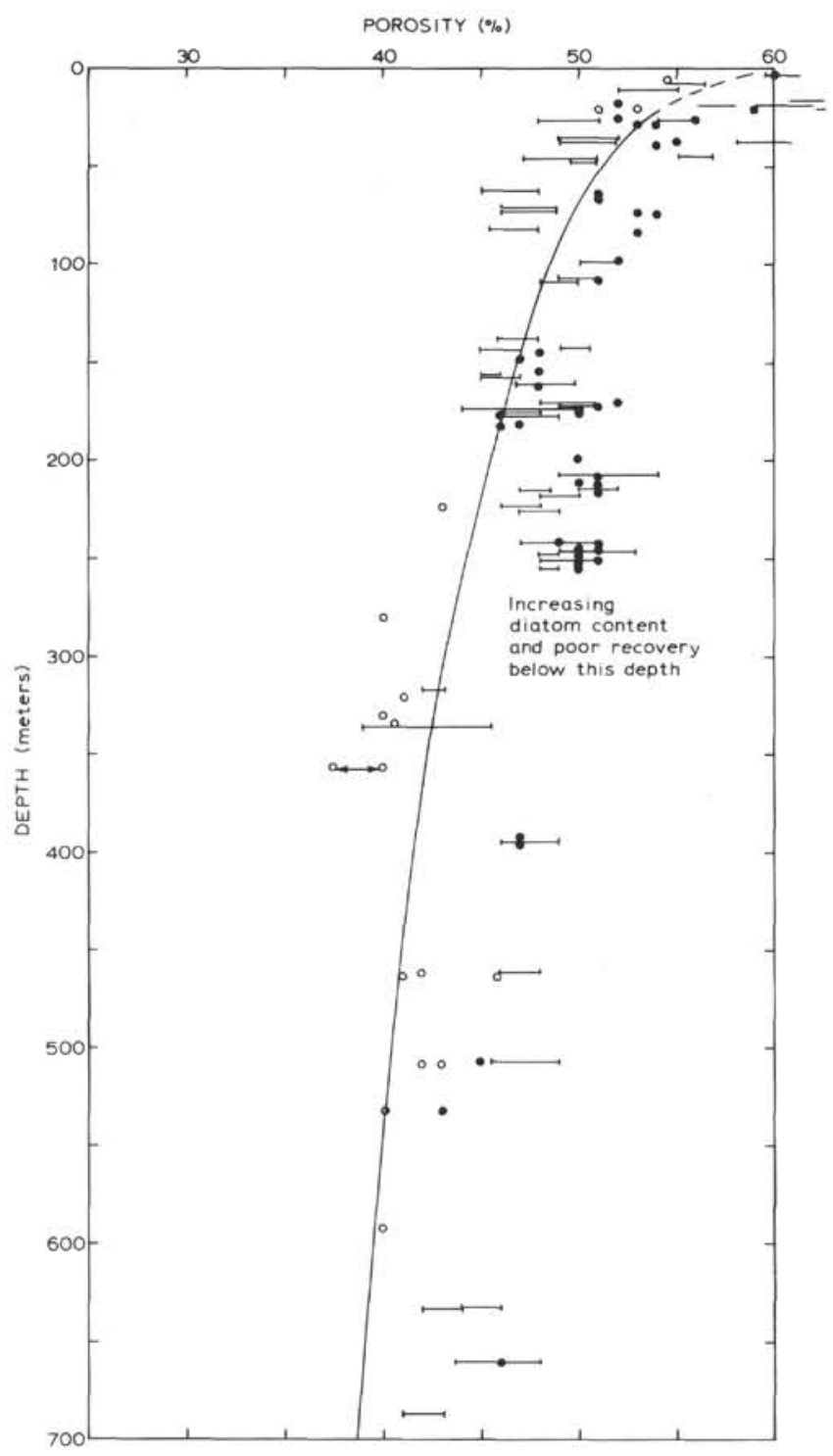

Figure 4. Porosity versus depth for Sites 178-179, Alaska Abyssal Plain. Symbols as in previous figures. The increase in diatom content below 290 meters made it difficult to find many acceptable values. Low porosities were read preferentially and therefore the graph is probably biased a little toward lower values.

McCulloh, Thane H., 1967. Mass properties of sedimentary rocks and gravimetric effects of petroleum and natural gas reservoirs. U.S. Geol. Survey Prof. Paper 528-A, $50 \mathrm{p}$.

McManus, D. A., 1970. Comparison of three methods of measuring or estimating sonic velocity in sediments. In McManus, D. A., Burns, R. E., et al., 1970. Initial Reports of the Deep Sea Drilling Project, Volume V. Washington (U.S. Government Printing Office).

Paulus, F. J., 1972. Leg 11 measurements of physical properties in sediments of the western north Atlantic and their relationship to sediment consolidation. In Hollister, C. D., Ewing, J. I., et al., 1972. Initial Reports of the Deep Sea Drilling Project, Volume XI. Washington (U.S. Government Printing Office).

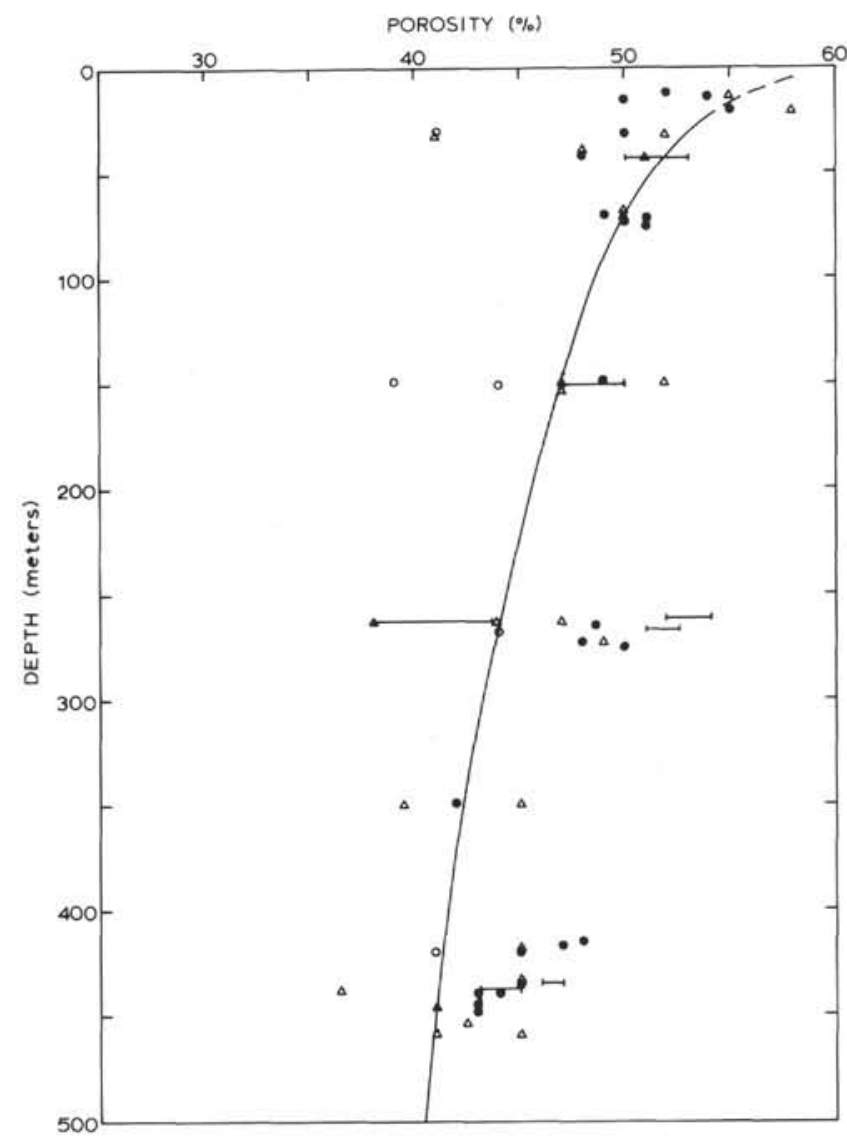

Figure 5. Porosity versus depth for Site 180, lower continental slope. Symbols as in previous figures. Porosity values of the sands are all from very fine, poorly sorted sand, some of which are ash. The core contained much gas below 5 meters making barrel averages unreliable without careful selection. The data are biased toward lower values.

Pimm, A. C., Garrison, R. E., and Boyce, R. E., 1971. Sedimentology synthesis: lithology, chemistry and physical properties of sediments in the northwestern Pacific Ocean. In Fisher, A. G., Heezen, B. C., et al., 1971. Initial Reports of the Deep Sea Drilling Project, Volume VI. Washington (U.S. Government Printing Office).

Richards, A. F., and Hamilton, E. L., 1967. Investigations of deep-sea sediment cores, III consolidation. Marine Geotechnique. A. F. Richards (Ed.). Urbana (University of Illinois Press).

\section{APPENDIX: EVOLUTION OF POROSITY MEASUREMENT PROCEDURES DURING LEG 18}

On previous Challenger cruises, absolute differences of 10 to 15 percent between GRAPE and syringe values have been reported (Paulus, 1972) and corresponding differences occur in Leg 18 data if they are similarly handled. The evaluation of Leg 18 porosity determinations and the resultant reduction of GRAPE-syringe porosity differences is described in this section.

The first contact any of the Leg 18 scientific staff had with the GRAPE and the syringe density technique was during the transit to 


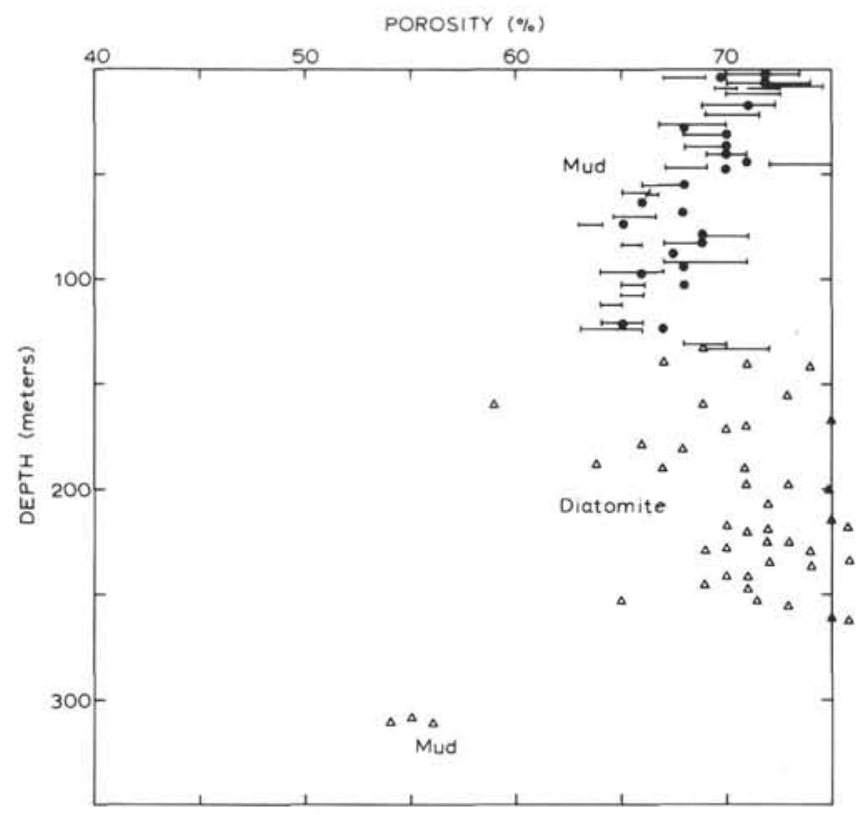

Figure 6. Porosity versus depth for Site 173, lower continental slope off California. Only syringe values are plotted below 170 meters because of grain density uncertainties caused by diatom content. Above 170 meters GRAPE-syringe differences have a mean deviation of 1.7 percent and this is probably the precision of syringe measurements in the diatomite also. At depths between 133 and 264 meters the porosity shifts 10 to 20 percent upward due to a diatom content from 50 to 90 percent.

our initial drilling site. During the cruise we went through a learning process and had to develop confidence in the GRAPE results, establish the syringe measurement precision, familiarize ourselves with the effects of core disturbance, and acquire a knowledge of the characteristics of the sediments encountered.

Standard procedures were used during the first part of Leg 18 These consisted of routinely running as many core sections through the instrument as time would permit (usually 2 or 3 sections per barrel). Syringe samples were systematically taken between 10 and $20 \mathrm{~cm}$ from the top of the core along with the carbon-carbonate sample. This syringe sample was compared with the range of GRAPE porosity for the barrel.

Some data were reduced during the third week at sea and the GRAPE-syringe differences were generally within 10 to 15 percent. These disappointing results provoked an effort to achieve greater accuracy. GRAPE porosity values commonly ranged from 15 to 20 percent which included the effects of voids and disturbed core or drilling slurries as well as lithologic changes. Attempts to correlate the syringe and GRAPE measurements more closely showed that the general irregularities of the GRAPE record and the accuracy with which a syringe sample point could be located on the GRAPE record were not sufficient for a good comparison. The Site 177 data were more carefully analyzed by distinguishing between porosities for sand, silt, and mud and by eliminating some of the undesired effects of disturbance, This led us to a questioning of the accepted syringe value accuracy, in spite of a new calibration of syringe volume radioed to Challenger.

At Site 178, the range between GRAPE and syringe values was narrowed to about \pm 4 percent; however, it appeared that syringe samples, although not visibly disturbed, might still be affected by drilling or sampling distortion. At Site 179, extra care was taken to select syringe samples where no visual disturbance had occurred. However, differences between GRAPE and syringe porosities fell short of expectations by ranging up to $13 \%$ even after all questionable data were rejected.

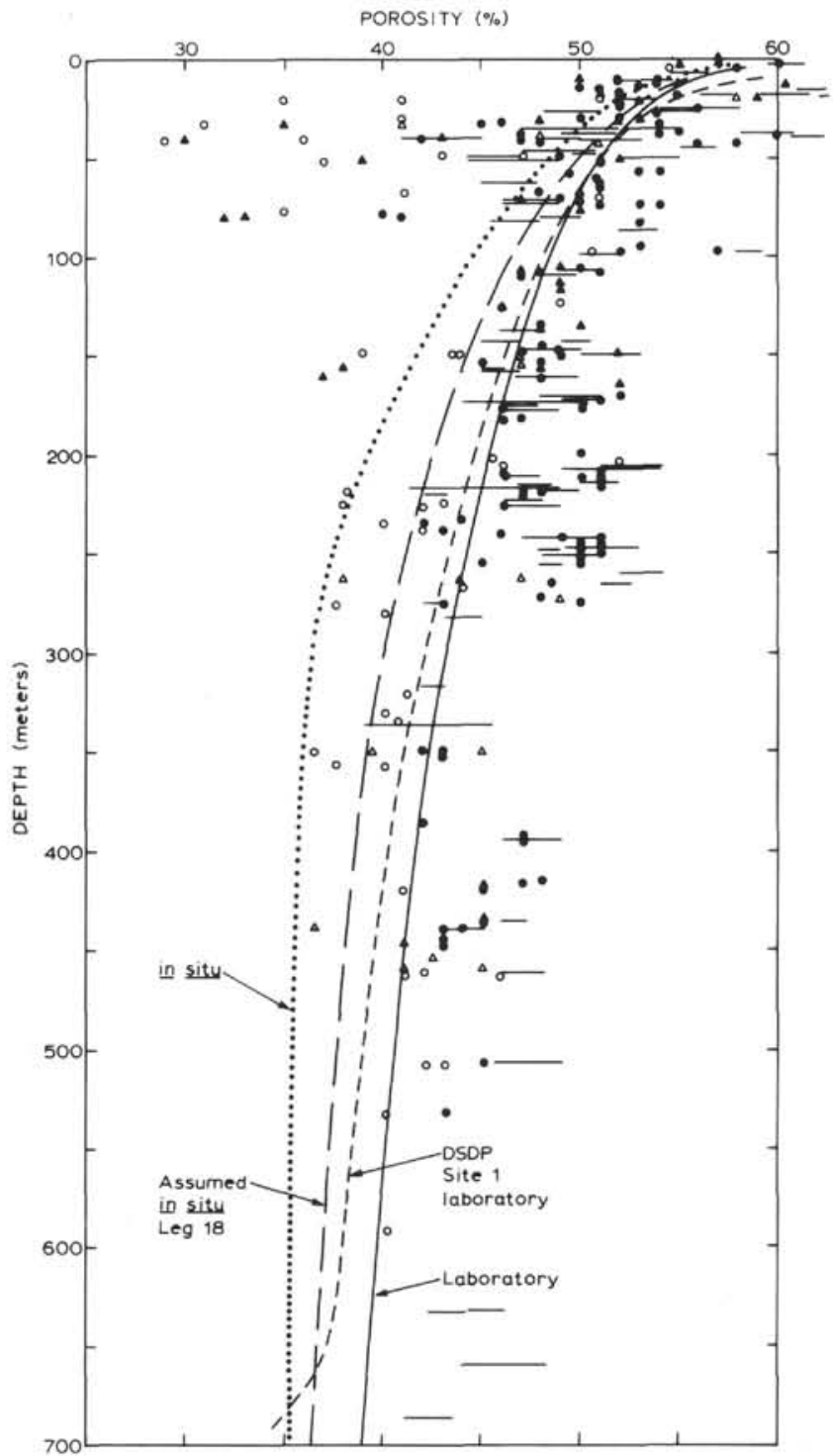

Figure 7. Summary graph of all porosities except those from Site 173. Symbols as on previous figures. General laboratory curve, in situ and Leg 18 assumed in situ curves, and curve from Site 1, at the base of the Sigsbee Escarpment are shown.

At Site 180 , pairs (and one triplet) of syringe samples were taken from segments of the core showing constant lithology and GRAPE values. Of forty-seven syringe samples, thirteen were rejected because of possible volume measurement errors. Additional samples were rejected when it was found that their position could not be located with certainty on the GRAPE record because the core position had shifted as a result of gas expansion and splitting procedures. Finally, only eight pairs and one triplet of samples (18 of the original 47) were accepted for comparison of GRAPE and syringe values. With these modified procedures a preliminary porosity difference of \pm 2 percent was found between the GRAPE and selected syringe values for Site 180 on board the ship. (On shore, analysis of all the syringe pair differences showed a range of 10 percent and a standard deviation of 3 percent). It was now obvious that multiple syringe samples from one spot were necessary to achieve a 2 percent comparison with the GRAPE, and that the GRAPE record had to be constant or undisturbed for 10 to $20 \mathrm{~cm}$ at the syringe sampling point. 


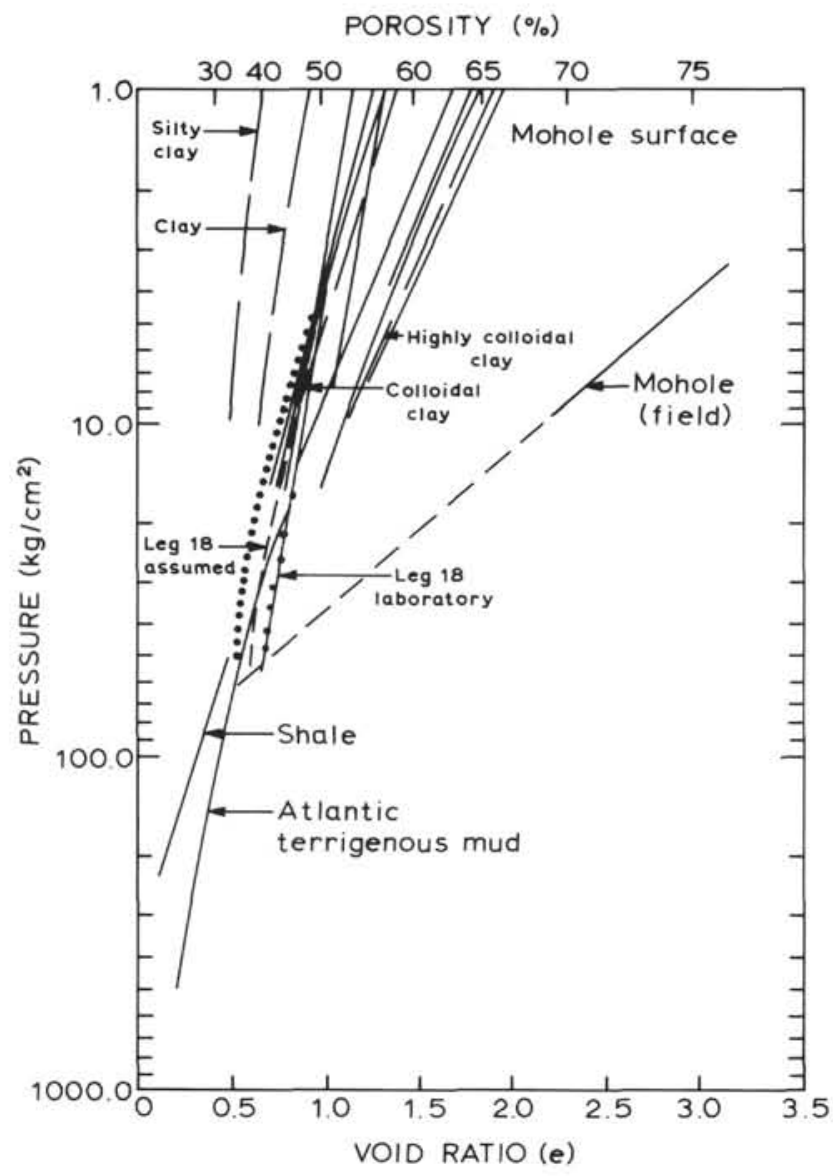

Figure 8. Summary e $\log P$ graph from Richards and Hamilton, 1967 with Leg 18 laboratory, assumed in situ, and in situ curves shown as solid, dashed and dotted lines, respectively.
At Site 181, even greater care was taken to select suitable sample pairs where the GRAPE record was constant and where grain densities were more certain. This resulted in a difference between syringe pair difference range of 7.5 percent, a mean deviation of 2.1 percent, and a standard deviation of 1.7 percent. The GRAPE-syringe differences for Site 181 have a maximum range of 3 percent, a mean deviation of 1.2 percent, and a standard deviation of 0.9 percent. From these data, it was quite obvious when a syringe value was in doubt or when the grain densities assumed in reduction of GRAPE records were probably in error.

As was mentioned previously, the close agreement between syringe samples from the middle of the cores and their corresponding GRAPE values, which included the outer and most frequently disturbed sediment, indicates that careful selection can eliminate the increases in porosity caused by coring disturbance. 